\title{
Bibliographical Notices:
}

A Dictionary of Practical Medicine: comprising General Pathology, the

Nature and Treatment of Diseases, Morbid Structures, \&c., by J JMES Copland, M. D., F. R. S., edited, with additions, by Charles A. Lee, M. D., part 1, New York, Henry G. Langley.

The above work needs no commendation at our hands; all who have seen it must admire it, for the extent and immense amount of the information it contains on every branch connected with the science of medicine. And the additions by Dr. Lee, consisting of the introduction of the American improvements, must greatly enhance its value in the eyes of American readers, as well as add to the stock of scientific medical knowledge to those of our transatlantic brethren, who can sufficiently lay aside their natural pride and prejudices, to view, with a calm and dispassionate eye, the labors and efforts of "Brother Jonathan" to heal the diseases, and relieve, as far as possible, the miseries and sufferings of mankind.

But there is another reason for calling special attention to this work, and that is its cheapness. In the language of the publisher, "the American edition, which will be comprised in twenty numbers, will punctually appear monthly ; forming, when finished, three handsome octavo volumes, price $\$ 10$, is one of the most valuable, as well as cheapest productions afforded to the medical profession."

The Cyclopodia of Practical Medicine.-The first number of this work is in our possession, and fully sustains its character and title of being a practical work.

Its subject matter is arranged alphabetically, and is treated on by men of the highest talent, standing, and practical experience in the medical profession.

It is edited by Drs. Forbes, Twedie, and Conolly. The American edition is published by Lea and Blanchard. Revised and with additions by Professor Dungleson. From such men and the extent of the work, embracing, as it does every thing valuable, in the whole circle of practical medicine. The medical community will thus have an opportunity of furnishing themselves with one of the most comprehensive publications known to the profession.

It will be completed in twenty-four parts, at 50 cents a part.

This work, however, is not only necessary and useful to the physician, but it also contains information that should be possessed by every dentist, and it is for the benefit of this last class of practitioners that this notice is more especially intended, and we most earnestly invite the attention of our professional brethren to it. 
The science of Dentistry is now acknowledged to be a necessary and essential part of the science of medicine. That it is the link-and an essential link in the great chain of medicine for preserving the health and relieving the sufferings of our afflicted fellow beings. And that it cannot hence be studied by and of itself, apart and independent of the other branches of medicine.

But further, the science of Dental Surgery is now zealously and industriously striving for an elevated stand; yes, for an equal stand, which is no more than her right, among the sister sciences. She is making noble efforts in every part of our country for the elevation of the profession-for raising it from the degraded condition which it has ton long occupied, and placing its members, by the light of scientific medical knowledge, on an equality with the other learned professions.

To this most desirable end, it gives us pleasure to report the fact, several times announced before in our Journal, and which, we humbly think, cannot too frequently be brought to the public eye, as well as before the profession itself, which is, the establishment of a college for the express purpose of educatıng and practically teaching young men, who shall thus go out suitably qualified to credit to it and themselves, honor to their profession and lasting benefit to the community.

\section{(HI iscellaneous Notices.}

Explanation.-It having been stated by some of the readers of the Journal, and with some degree of prejudice and blame to the Washington editor, that the remarks made by him in his "gossip," of the last March number, as to the manner in which some men get business, were uncalled for, as far as they alluded to two persons, who have within the last two years associated themselves together, and in justice to all parties, we make the following explanation :

Dr. J. Smith Dodge, late of the Bowery, but now of Bond street, New York, in 1842, employed as an assistant in mechanical dentistry, a person who was then known as Luther Parmelee, late machinist, and in some few months afterwards there appeared on a plate in Bond street, "Dodge \& Parmely, dentists." During the ensuing session of congress, there also appeared in the newspapers an advertisement of "Dodge \& Parmely, dentists, of Bond street, New York," offering their services to the citizens, \&c. of Washington. In conversation, Dr Dodge stated to the Washington editor, that his partner was not either Dr. E. or Dr. J. Parmly, of Bond street, "but one of the same family;" and it was upon hearing from the Drs. Parmly, subsequently, that they had never seen Dr. Dodge's partner nor known any thing of him, farther than hearing from Dr. D., that such a person was 